\title{
ARTIGOS
}

Submetido em 12.06.2016. Aprovado em 03.04.2017

Avaliado pelo processo de double blind Review. Editor Científico: Adriano Peixoto

DOI:http://dx.doi.org/10.1590/So034-759020170504

\section{DIAGNÓSTICO E ANÁLISE DAS COMPETÊNCIAS DOS CONSELHEIROS DE ADMINISTRAÇÃO}

\author{
Diagnosing and analyzing of board directors' competences \\ Diagnóstico y análisis de las competencias de los consejeros de Administración
}

\begin{abstract}
RESUMO
Um dos problemas-chave ao se estruturar um conselho de Administração é arquitetar o perfil de competências dos membros do conselho. Este estudo parte da teoria de competências para analisar o escopo de competências individuais dos conselheiros de Administração. Procura-se responder: Quais são as competências requeridas aos conselheiros de Administração em empresas de capital fechado? Quais características dos conselheiros podem ser prejudiciais à performance do próprio conselheiro e, em última instância, do conselho como órgão colegiado e da empresa? Para isso, foi feito um estudo com o método de grounded theory, baseado em entrevistas com 12 conselheiros de Administração de empresas de capital fechado, que possuem no mínimo cinco anos de experiência como conselheiros e extensa carreira como executivos da alta Administração. As proposições e modelo teórico proposto apontaram um conjunto maior de competências comportamentais com relação às competências técnicas, o que complementa os estudos anteriores sobre o tema.
\end{abstract}

PALAVRAS-CHAVE | Governança corporativa, competências, conselho de Administração, grounded theory, competências comportamentais.

artur.neves@uol.com.br

Mestre em Administração

- Governança Corporativa pela Laureate International Universities - São Paulo - SP, Brasil

\section{PAULO URBANI CARVALHINHA} paulo.carvalhinha@uol.com.br Mestre em Administração - Governança Corporativa pela Laureate International Universities - São Paulo - SP, Brasil

\section{PATRICIA MORILHA MURITIBA} patricia.muritiba@ufabc.edu.br Professora da Universidade Federal do $A B C$, Centro de Engenharia, Modelagem e Ciências Sociais - São Bernardo do Campo - SP, Brasil

\section{SERGIO NUNES MURITIBA} smuritiba@gmail.com Sócio-proprietário do Instituto GEPRA de Inovação para Proprietários - São Paulo - SP, Brasil

\begin{abstract}
A key issue when assessing a board of directors' composition is defining the profile of directors' desirable competences. This study follows competence theory to analyze the role of individual competences of board directors. We aim to answer the following questions: which are the required competences of board directors in non-listed companies, and what characteristics might lead to poor individual performance and adversely affect a board's overall performance. To investigate these questions, a grounded theory- based study was conducted involving interviews with twelve board directors who had at least five years of experience as directors and extensive careers as top management executives. Results of the study led to a theoretical model which identifies a set of behavioral competences that add to previous studies on this subject.
\end{abstract}

KEYWORDS / Corporate governance, competences, boards of directors, grounded theory, behavioral competencies.

\section{RESUMEN}

Uno de los problemas clave al estructurar un consejo de Administración es diseñar el perfil de competencias de los miembros del consejo. Este estudio parte de la teoría de competencias para analizar el alcance de las competencias individuales de los consejeros de Administração. Se trata de responder: ¿Cuáles son las competencias requeridas de los consejeros de Administración en empresas de capital cerrado? ¿Qué características de los consejeros pueden ser perjudiciales para la performance del propio consejero y, en última instancia, del consejo como órgano colegiado y de la empresa? Para ello, se realizó un estudio con el método de grounded theory, basado en entrevistas con 12 consejeros de Administración de empresas de capital cerrado que poseen, como mínimo, cinco años de experiencia como consejeros y una extensa carrera como ejecutivos de la alta Administración. Las proposiciones y el modelo teórico propuesto indicaron un conjunto mayor de competencias comportamentales con relación a las competencias técnicas, lo que complementa los estudios anteriores sobre el tema.

PALABRAS CLAVE / Gobernanza corporativa, competencias, consejo de Administración, grounded theory, competencias conductuales. 


\section{INTRODUÇÃO}

No ambiente do sistema da governança corporativa, os conselhos de Administração assumiram um papel significativo nos últimos anos (Anderson, Melanson, \& Maly, 2007). Uma das questões chave para se estruturar um conselho de Administração é a escolha dos conselheiros; essa escolha deveria basear-se na correta composição de competências do conselho de Administração nas empresas (Morilha, 2014).

O conselho de Administração é um órgão fundamental da governança corporativa - tema que assumiu importância na medida em que mais empresas envolviam-se em escândalos corporativos e o mercado passava por uma crise de confiança nas organizações (Child \& Rodrigues, 2003). Isso gerou uma demanda maior por melhores competências do alto escalão da empresa - o que poderia acarretar melhores decisões tomadas e, por consequência, a perenidade das organizações (Hambrick \& Mason, 1984).

A definição clássica de competência veio do artigo seminal de McClelland (1973), segundo o qual a competência extrapola os conhecimentos que uma pessoa pode possuir para englobar também suas habilidades, que são os conhecimentos colocados na prática e atitudes que são resultados da somatória do conhecimento e habilidades. A afirmação, no entanto, é de difícil conceitualização, devido às suas raízes oriundas de diferentes vertentes filosóficas, científicas e epistemológicas. Para esse estudo, define-se competência como o conjunto de características do indivíduo relacionadas à entrega de valor para a organização (Dutra, 2002). 0 foco deste trabalho compreende o conselheiro que atua em empresas de capital fechado.

Existe uma grande quantidade de estudos dedicados à personalidade do CEO nas organizações (Nadkarni \& Herrmann, 2010; Resick, Whitman, Weingarden, \& Hiller, 2009), mas o mesmo esforço ainda não foi feito para os conselhos de Administração. As competências dos conselheiros começaram a ser estudadas na última década, como em Collins, (2004), Charan, Useem e Carey, (2014), e Morilha, (2014), mas ainda se sabe pouco sobre elas.

Considerando o exposto anteriormente, este estudo tem por objetivo identificar e analisar as competências individuais para os conselheiros de Administração. O foco deste estudo está nos conselheiros de empresas de capital fechado.

Procura-se responder às seguintes questões de pesquisa:

QP1: Quais são as competências dos conselheiros de Administração em empresas de capital fechado?

QP2: Quais são as características dos conselheiros que podem ser prejudiciais à performance do conselheiro e, em última instância, do conselho como órgão colegiado e da empresa?
Ao responder a essas questões de pesquisa, pretende-se também propor um modelo qualitativo que identifique categorias de competências requeridas aos diferentes perfis de conselheiros.

Para atender aos objetivos propostos, foi realizado um estudo com o método de grounded theory, baseado em entrevistas com 12 conselheiros de Administração de empresas de capital fechado, que possuem no mínimo cinco anos de experiência como conselheiros e extensa carreira como executivos da alta Administração.

Espera-se, ao final deste estudo, contribuir com o processo de arquitetura e constituição de conselhos de Administração de maior competência e para o estudo da governança corporativa, com o melhor entendimento das competências essenciais dos conselheiros de Administração.

\section{REFERENCIAL TEÓRICO}

O conselho de Administração é entendido como o principal componente do sistema da governança corporativa, e seu papel é ser o elo de relacionamento entre a propriedade e a gestão (Instituto Brasileiro de Governança Corporativa [IBGC], 2015). Este é um órgão mais comum em empresas de grande porte, e especialmente naquelas de capital aberto, para as quais é obrigatório.

Entre as principais discussões que o conselho de Administração deve abordar, estão aquelas relacionadas a, por exemplo, exigências dos acionistas quanto ao desempenho da organização e atenção a prestação de contas (Sonsini, 2011).

Embora as competências do conselheiro de Administração não tenham sido extensamente pesquisadas, outras características da formação do conselho são muito exploradas, como o tamanho ideal do conselho (Yermack, 1996).

Esse é um assunto controverso, já que a escolha dos conselheiros seria fortemente influenciada pelas características da empresa onde o conselho atuaria. Por exemplo: empresa de controle unifamiliar, multifamiliar ou mesmo de arranjo misto tem características de negócios e demandas diferentes, que podem influenciar a escolha de diferentes tipos e perfis de conselheiros e de diretores, para atender necessidades da governança (Sur, Lvina, \& Magnan, 2013).

Assim, os estudos anteriores trazem uma ampla gama de discussões sobre como o conselho de Administração deveria ser formado - em termos de tamanho, perfis de conselheiros e diferenças das empresas - mas não se sabe ainda muito sobre quais características pessoais esses conselheiros deveriam apresentar. É nesse contexto que se escolheu o foco 
das competências individuais para se tratar dos conselhos de Administração.

\section{Competências}

O conceito de competência tem sido utilizado em diferentes contextos - macro e micro - e com diferentes abordagens, o que confere a ele complexidade na sua definição e operacionalização.

Nos contextos macro e micro, competência pode ser entendida como característica inerente ao indivíduo (campo micro) e inerente à organização (campo macro). Esse último refere-se ao campo da Estratégia Organizacional, no qual o termo competência aparece derivado da escola de visão baseada em recursos (Lado \& Wilson, 1994). Nesse contexto macro, o termo comumente utilizado é o de competência essencial, que se refere aos principais recursos da organização que a diferenciam dos concorrentes e são difíceis de imitar (Prahalad \& Hamel, 1990).

No contexto micro - tratado neste estudo - a competência é analisada no nível do indivíduo. Assim, competência passa a ser uma característica do indivíduo em si, e não da organização. No entanto, existe uma ligação entre as competências individuais e as competências essenciais da organização: de maneira simplificada, as competências essenciais da organização se desdobrariam em competências organizacionais, tais como competências das áreas de Negócios, e, a partir daí, seria possível fazer o inventário do que se é esperado dos indivíduos que trabalham nessa organização, em virtude da própria estratégia da organização e suas competências essenciais (Brandão et al., 2008). Essa, embora seja intuitiva, não é uma tarefa simples, e os estudos anteriores mostram que há muita subjetividade envolvida ao se traduzirem estratégias organizacionais em competências individuais, e esse link pode se perder no caminho (Fleury \& Fleury, 2004).

No nível micro, o das competências individuais, ainda, o tema recebeu influências de diferentes escolas e abordagens, o que torna complexa sua operacionalização.

Uma das origens do estudo das competências individuais foi na Psicologia, em trabalhos que embasavam a necessidade de identificar e selecionar os melhores profissionais para as organizações, como no estudo seminal de McClelland (1973). As organizações, nessa época, faziam usualmente a seleção de profissionais com base no quociente de inteligência ou na sua experiência profissional. McClelland questionou essa abordagem - para ele, além da inteligência, que ele chama de “conhecimento", os profissionais adequados possuem também habilidades, que são a capacidade de colocar o conhecimento em prática e atitudes, a vontade de colocar suas habilidades em prática, ou por meio de comportamentos adequados. Ele definiu competência como o conjunto de conhecimentos, habilidades e atitudes, definição que ficou conhecida pelo acrônimo CHA.

Os estudos das competências individuais foram também difundidos na França, onde Zarifian é um dos expoentes. 0 autor trabalha com a ideia de que a competência de um indivíduo só faz sentido se for expressa dentro de uma situação aplicável, seja na empresa onde trabalha ou em outro contexto (Zarifian, 2012). A competência ocorre, portanto, na encruzilhada entre o que a empresa (ou sociedade) demanda e o que as pessoas podem oferecer. Isso tem algumas implicações sobre o conceito de competência. Primeiramente, a competência depende da entrega - não é suficiente que um indivíduo seja bom em determinada coisa, mas ele também precisa colocar isso em prática e agregar valor à organização onde atua. Em segundo lugar, a competência varia conforme as necessidades das organizações, que são mutáveis conforme sua estratégia muda ao longo do tempo e das variações de competição e ambiente em que a organização se encontra.

Considerando-se, então, que a competência representa entrega do indivíduo, agregando valor à organização onde atua e, consequentemente, às competências organizacionais e essenciais da empresa, isso pressupõe um sistema de gestão por competências que objetive selecionar profissionais com as competências demandadas pela organização, incentivar o desenvolvimento dessas competências e avaliar o desempenho dos indivíduos com base nelas, como o sistema que algumas empresas têm adotado (Albuquerque \& Oliveira, 2010).

Assim, o mapeamento das competências deveria considerar as características das organizações que demandam tais competências (Brandão \& Babry, 2005). As competências mapeadas, então, têm seu uso nas políticas de seleção, treinamento, compensação e avaliação do desempenho, que passam a ser alinhadas às competências essenciais das organizações. Por exemplo, existe uma relação de interdependência entre a gestão por competências e a gestão de desempenho, podendo complementar-se em um contexto mais amplo de gestão organizacional - gestão de desempenho baseada nas competências (Brandão \& Guimarães, 2001).

É esse mapeamento que este estudo pretende desenvolver, considerando as necessidades que as organizações de capital fechado possuem com relação aos seus conselheiros de Administração e que, a partir do rol de competências esperadas desses conselheiros, é possível direcionar os esforços para selecionar, remunerar e avaliar o desempenho desses conselheiros. 


\section{Competências dos conselheiros de Administração}

O capital intelectual da empresa é gerado não somente pelos funcionários dela, mas também pelos agentes reguladores, como o conselho de Administração, por meio das competências dos conselheiros e dos relacionamentos que eles possuem (Berezinets, Garanina, \& Ilina, 2016).

Os conselheiros independentes são importantes agentes do sistema de governança corporativa. Sua presença é peçachave para a redução do problema de agência. Analisando holisticamente, deve-se verificar o capital intelectual do conselheiro, o seu conhecimento sobre a companhia como a história e constituição da empresa e seus envolvimentos legais. Elementos como comportamento do conselheiro também devem ser levados em conta (Nicholson \& Kiel, 2004).

Muito embora as características que um conselheiro deveria possuir para desempenhar melhor sua função façam parte de códigos de governança corporativa tradicionais, o estudo acadêmico das competências dos conselheiros de Administração é mais recente,. Sabe-se que a experiência profissional e formação do conselheiro influenciam as políticas de divulgação de informações e transparência das organizações (Enache, Parbonetti, \& Srivastava, 2015), o que denota a relevância desse tema para códigos de governança.

Por exemplo, o código do IBGC apresenta uma lista de características que fazem parte da qualificação mínima para um conselheiro. De acordo com o órgão (IBGC, 2015), o conselheiro precisa no mínimo ter: alinhamento com os valores da organização e seus códigos de conduta, capacidade de defender seu ponto de vista a partir de julgamento próprio, disponibilidade de tempo e motivação; deve, ainda, adicionalmente possuir: visão estratégica, conhecimento das melhores práticas de governança corporativa, capacidade de trabalho em equipe, capacidade de ler e entender os relatórios financeiros, noções de legislação societária e percepção do perfil de risco da organização.

O que se nota na abordagem dada pelo código de melhores práticas o IBGC é que existe um rol de conhecimentos técnicos que fazem parte da formação do conselheiro. Estudos científicos também relacionaram uma parcela significativa de conhecimentos técnicos na formação do conselheiro. Cocks et al. (2015) basearam-se em um levantamento de autoavaliações dos próprios conselheiros, que indicaram que estes precisam ter as seguintes competências: entender a estratégia da empresa, conhecer procedimentos legais, habilidades de liderança e trabalho em equipe, e grau de comprometimento do conselheiro. No entanto, além dos conhecimentos técnicos sobre estratégia e legislação, mesmo esses estudos já denotam um componente comportamental importante, tal como o trabalho em equipe.

Esse alinhamento entre competências comportamentais e técnicas foi também base do modelo de Hambrick et al. (2015). Eles argumentaram que a capacidade de monitoramento eficiente da empresa é maior quando os conselheiros possuem certas qualidades, como independência, conhecimento no campo da empresa onde atuam, habilidade de devotar tempo e atenção adequados, e motivação.

Como uma etapa preliminar do presente estudo, buscou-se identificar, nos estudos científicos sobre conselheiros, características que fossem possíveis competências.

0 conselho de Administração deve atuar com equilíbrio, no sentido de perceber os momentos em que necessita estar mais ativo na empresa e os momentos em que deve apenas monitorar. 0 conselho, dependendo de sua atuação, pode ajudar a empresa a ter sucesso, mas pode também fracassar junto com ela (Charan et al., 2014).

Para que um conselheiro possa agregar valor ao colegiado ou à instituição, ele deve primeiramente conhecer os seus limites e as suas competências que podem ser úteis nessa relação de aconselhamento. Deve também entender quais as reais motivações que foram determinantes para ser escolhido para exercer tal função (Morilha, 2014).

Entre os fatores que podem interferir na eficiência do conselheiro, estão a dificuldade de estabelecer um relacionamento com seus pares e a dificuldade de estabelecer um limite à sua necessidade de informação. Esse fator pode ser um impeditivo à tomada de decisão, pois o conselheiro poderá interessar-se em receber mais informações sobre o assunto unicamente para atender à sua curiosidade pessoal (Collins, 2004).

Foram listadas também, como competências dos conselheiros, a identificação do compromisso profissional, a utilização de coerência na averiguação dos fatos, bem como compartilhamento da responsabilidade (Lucas et al., 2009).

Algumas competências listadas pelos próprios conselheiros são: integridade, neutralidade, responsabilidade, criticidade, idoneidade (Aragão, 2003).

A competência de saber conversar de maneira objetiva é listada como a mais importante para os conselheiros; outras competências citadas foram em relação a conhecer as leis necessárias para o trabalho (Andre, 2010).

Yoshikawa e Hu (2015) propuseram que a clareza que o conselheiro tem sobre seu papel na organização pode estar relacionada a um comportamento ético e colaborativo desse conselheiro na empresa. 
Competências dos conselheiros independentes, em dois estudos de caso, foram: habilidade de entender questões de governança, habilidade de apresentar as preocupações dos acionistas, habilidade de prover visão estratégica, habilidade de controlar projetos, conhecimento específico das operações da empresa, habilidade de mitigar riscos ambientais e sociais, habilidade analítica de relatórios de contabilidade social (Alshareef \& Sandhu, 2015).

O agrupamento das competências desses estudos citados encontra-se no Quadro 1.

\section{Quadro 1. Quadro teórico}

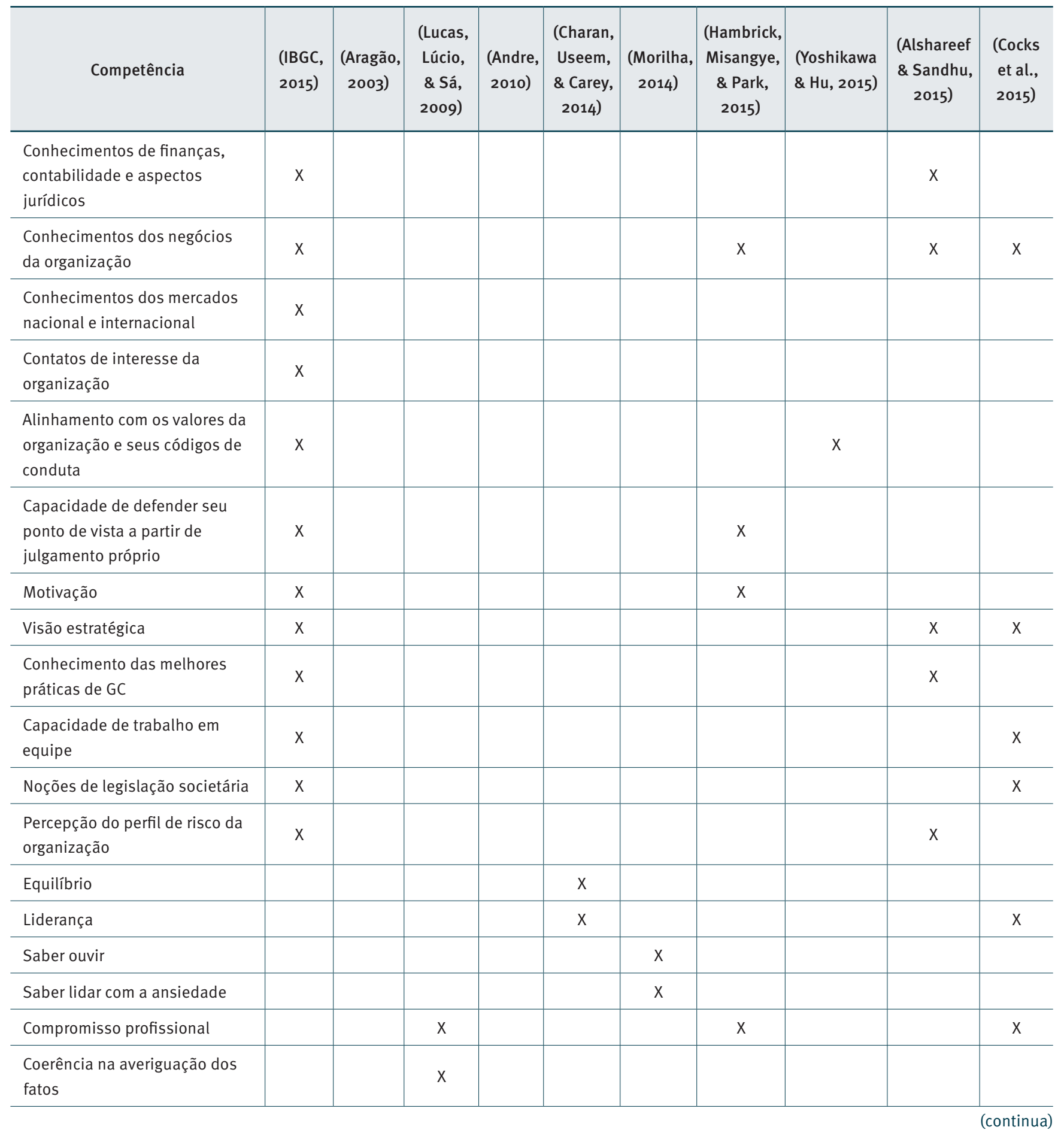


Quadro 1. Quadro teórico

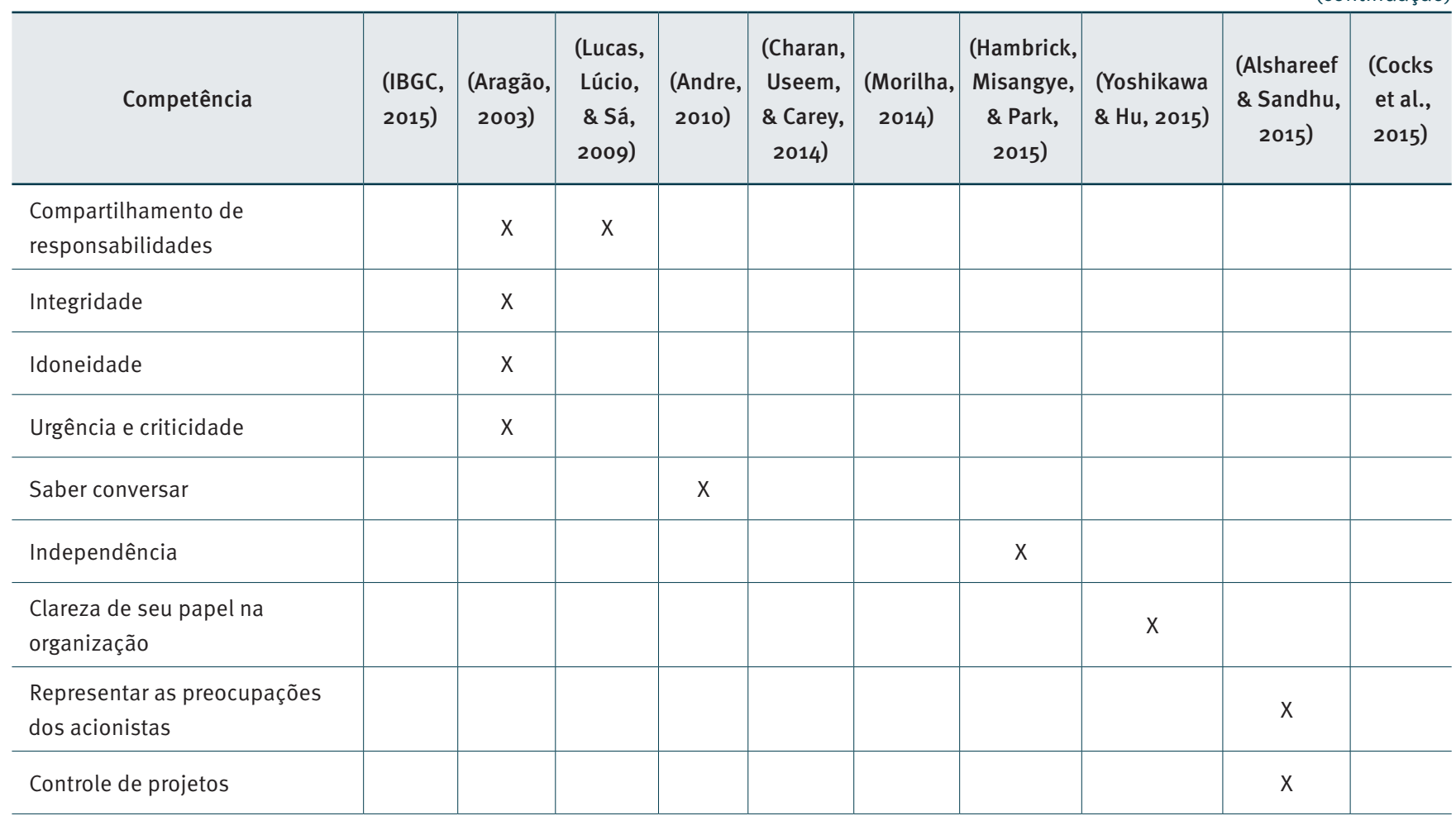

A síntese da literatura apresentada no Quadro 1 mostra duas características importantes para a atual pesquisa. Primeiro, uma das fontes que mais relaciona competências dos conselhos é o IBGC (2015), que não é uma fonte teórico-científica, mas sim um órgão regulamentador da área. Optou-se por deixá-lo relacionado no quadro teórico a título de comparação com os resultados dos estudos anteriores, que possuem menor amplitude de competências. Em segundo lugar, nota-se que os estudos anteriores encontrados não possuem muitas competências repetidas - o que denota o baixo nível de saturação teórica obtida pelos estudos anteriores da área e a necessidade de se desenvolverem mais estudos robustos sobre o assunto.

\section{PROCEDIMENTOS METODOLÓGICOS}

Para atender aos objetivos deste trabalho, foi escolhido o método da grounded theory, que se trata de um método indutivo no qual o pesquisador busca o desenvolvimento de teoria a partir de uma pesquisa qualitativa (Strauss \& Corbin, 1997).

Internacionalmente, esse método já é um dos mais usados na pesquisa qualitativa, e vem crescendo muito seu uso em estudos nacionais. Esse método foi desenvolvido pelos sociólogos Glaser e Strauss (1967), sendo um dos métodos mais recomendados por journals de grande impacto como o Academy of Management Journal, que, inclusive, publicou em um editorial específico o fomento da sua utilização para a geração de bons estudos qualitativos (Pratt, 2009).

A grounded theory é um método qualitativo que pode ser bastante utilizado nas ciências sociais (Martin \& Turner, 1986). O seu diferencial em relação a outros estudos qualitativos é que nele se usam os elementos: conceitos, categorias e proposições. No momento em que se analisam os dados coletados, eles indicam a existência de conceitos e conjuntos de conceitos que são agrupados em categorias; isso permite ao pesquisador relacionar as categorias obtidas com a teoria, o que lhe possibilita a gerar proposições (Charmaz \& Belgrave, 2012).

Anteriormente à coleta de dados, foi realizada uma revisão da literatura, buscando identificar quais competências essenciais são comumente requisitadas para o exercício do papel de conselheiro de Administração. No entanto, para que o entrevistado possa expressar-se espontaneamente sobre determinado assunto, o roteiro de entrevista em grounded theory é normalmente composto por questões abertas. As pesquisas foram conduzidas mediante a utilização de um protocolo de entrevista semiestruturada com perguntas abertas e relacionadas com os objetivos deste trabalho, conforme apresentado no Quadro 2. 


\section{Quadro 2. Protocolo de entrevista}

\begin{tabular}{l|l}
\hline Questões de pesquisa & Questões da entrevista \\
\hline $\begin{array}{l}\text { QP1. Quais são as competências dos conselheiros de Administração } \\
\text { em empresas de capital fechado? }\end{array}$ & $\begin{array}{l}\text { Quais, na sua opinião, são as principais competências do } \\
\text { conselheiro e do conselho em empresas familiares (cite a } \\
\text { competência, uma explicação sobre ela, e o porquê da relevância } \\
\text { dessa competência, exemplos etc.) }\end{array}$ \\
\hline $\begin{array}{l}\text { QP2. Quais são as características dos conselheiros que podem ser } \\
\text { prejudiciais à performance do conselheiro e, em última instância, do } \\
\text { conselho e da empresa? }\end{array}$ & $\begin{array}{l}\text { Quais são, na sua opinião, os pontos negativos, ou gaps de } \\
\text { competência que podem atrapalhar e afetar negativamente a } \\
\text { performance do conselheiro, e, em última instância, do conselho e } \\
\text { da empresa? }\end{array}$ \\
\hline
\end{tabular}

\section{Escolha da amostra teórica}

O universo do estudo compreende conselheiros que atuam em empresas de capital fechado brasileiras. Para compor a amostra desta pesquisa, foram selecionados, por conveniência, 12 conselheiros que atuam em empresas brasileiras de capital fechado, de diferentes portes e estruturas societárias familiares ou multifamiliares.

O tamanho do universo de estudo é de difícil delineamento. No entanto, esta é uma pesquisa qualitativa, e o objetivo do estudo é contribuir com a proposição de modelos que possam ser testados em futuros estudos utilizando método de grounded theory, e não tem como objetivo construir novas teorias com o menor erro amostral possível. Nesse caso, a amostra do universo precisa ter representatividade na teoria estudada, o que é chamado de theoretical sampling, independentemente de ser representativa do universo (Breckenridge \& Jones, 2009).

A amostra de conselheiros de Administração considerada para este estudo foi selecionada por conveniência, visto a possibilidade de realização de entrevistas, que foram conduzidas pessoalmente com cada membro da amostra. A amostra considerada não é representativa do universo de estudo e deverá ser reavaliada, para que se obtenham dados e informações que respondam às questões de pesquisa teóricas. Por outro lado, no procedimento de grounded theory, a amostra não deve visar à representatividade, mas sim à coerência teórica com o fenômeno estudado - o que pode ser chamado de "amostra teórica" (Stern, 1980). Esse tipo de amostra como é o caso deste estudo - deve ser capaz de prover informações valiosas sobre o fenômeno em observação.

\section{Procedimentos de coleta de dados}

A coleta de dados foi realizada por meio de entrevistas e teve como objetivo obter respostas com o maior volume de informações e detalhes possível sobre o assunto. Essas entrevistas objetivam obter informações que ajudem a construir uma análise qualitativa a partir de um roteiro semiestruturado, que foi classificado por Bardin (2011) como entrevistas semidiretivas.

Parry (1998) propôs que as pesquisas de diagnóstico de competências poderiam basear-se em perguntas abertas que tomassem como base a percepção de especialistas no assunto para o levantamento das competências. Esse foi o procedimento utilizado neste estudo.

As entrevistas foram previamente agendadas com os conselheiros, conduzidas pessoalmente e também gravadas, com autorização do entrevistado. Essas gravações possibilitam que as entrevistas sejam transcritas e analisadas de maneira individual e comparadas de modo coletivo. As entrevistas tiveram duração média de 35 minutos.

\section{Procedimentos de análise dos dados}

0 procedimento de análise de dados foi realizada por codificação, que é uma técnica que compõe os pilares da grounded theory (Strauss \& Corbin, 1997). Os dados e conceitos analisados nas entrevistas foram as competências requeridas aos conselheiros de Administração em empresas de capital fechado.

As entrevistas foram transcritas literalmente, e isso gerou um documento de 35.680 palavras. Descontando-se trechos da entrevista que tratavam de assuntos diversos não relacionados com o tema, além de trechos de falas do entrevistador, chegou-se a 18.756 palavras, das quais 9.500 palavras foram trechos efetivamente codificados para fins de levantamento das competências.

Para análise do material coletado, foram utilizadas duas técnicas de codificação: código seletivo e código aberto. $\mathrm{Na}$ técnica de código seletivo, os códigos foram selecionados por blocos segundo os procedimentos dessa técnica. Na técnica de código aberto, os códigos foram gerados pelo pesquisador. Essa técnica possui confiabilidade a partir do momento em que dois ou mais pesquisadores conferem esses códigos. Esse procedimento foi aplicado neste estudo - procedimento 
chamado de inter rater reliability (Singleton \& Straits, 1999) foi feita a validação dos códigos por três pesquisadores, e a atribuição de categorias foi finalizada apenas quando se obteve consenso entre os três. Também buscou-se adequar a redação das competências à taxonomia dos objetivos educacionais de Bloom (Rodrigues, 1998). Esse procedimento visa facilitar a descrição das competências de modo a favorecer sua mensuração.

Após a codificação das informações, foi realizada a comparação com a teoria existente, de maneira a elaborar um modelo teórico suportado na relação entre os dados obtidos. Buscou-se, no questionamento aos entrevistados, identificar competências que se relacionassem positivamente com a performance do conselheiro, e outros fatores que tivessem relação negativa com tal performance. De posse das informações analisadas, propõe-se um modelo teórico que apresenta as proposições do estudo graficamente, ao final da apresentação e análise dos resultados.

\section{APRESENTAÇÃO E ANÁLISE DOS RESULTADOS}

Foram entrevistados 12 conselheiros membros de conselhos de Administração com idade média de 59 anos, contando entre 52 e 67 anos. Dos 12 entrevistados, apenas um era do sexo feminino.
Quanto à experiência da amostra em conselhos de Administração, verifica-se que são todos conselheiros experientes que possuem, em média, 12 anos de experiência.

No que se refere à formação acadêmica dos entrevistados, 40\% têm sua formação em administração de empresas, $20 \%$, em ciências contábeis, $20 \%$, em engenharia, $13 \%$, em direito e $7 \%$, em economia.

No que se refere às principais experiências e cargos ocupados anteriormente pelos entrevistados, houve destaque para os cargos de gestor de empresas de consultoria, com $37 \%$, e CEO, com $27 \%$

Quanto ao número de conselhos nos quais os entrevistados estavam atuando nesse momento, observa-se que a maioria (84\%) está entre dois e três conselhos, e $8 \%$ atuando em seis conselhos. Oito por cento deles não estão atuando em conselhos de Administração, mas sim em comitê de auditoria.

\section{Competências dos conselheiros de Administração}

A primeira questão de pesquisa visava identificar as competências dos conselheiros de Administração em empresas de capital fechado.

A Tabela 1 apresenta os resultados codificados da análise para essa questão.

\section{Tabela 1. Competências do conselheiro de Administração}

\begin{tabular}{|c|c|c|c|c|c|c|c|c|c|c|c|c|c|}
\hline 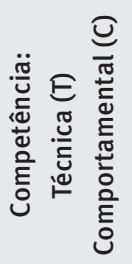 & $\begin{array}{l}\text { Competências do } \\
\text { conselheiro de } \\
\text { Administração }\end{array}$ & 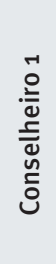 & 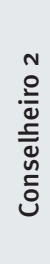 & 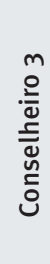 & 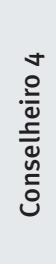 & 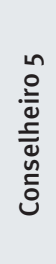 & 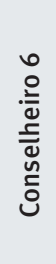 & 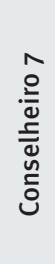 & 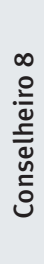 & 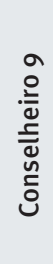 & 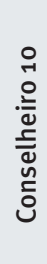 & 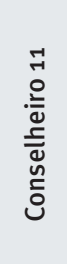 & 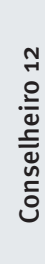 \\
\hline C & $\begin{array}{l}\text { Demonstrar capacidade de } \\
\text { atuar em grupo de maneira } \\
\text { cooperativa e colaborativa }\end{array}$ & & 2.1 & 3.1 & & 5.5 & 6.1 & & & 9.6 & & & \\
\hline $\mathrm{T}$ & $\begin{array}{l}\text { Demonstrar } \\
\text { conhecimentos práticos } \\
\text { sobre conselhos de } \\
\text { administração e } \\
\text { governança corporativa } \\
\text { (GC) }\end{array}$ & & & 3.4 & & & & & & & & 11.6 & \\
\hline
\end{tabular}


Tabela 1. Competências do conselheiro de Administração

(continuação)

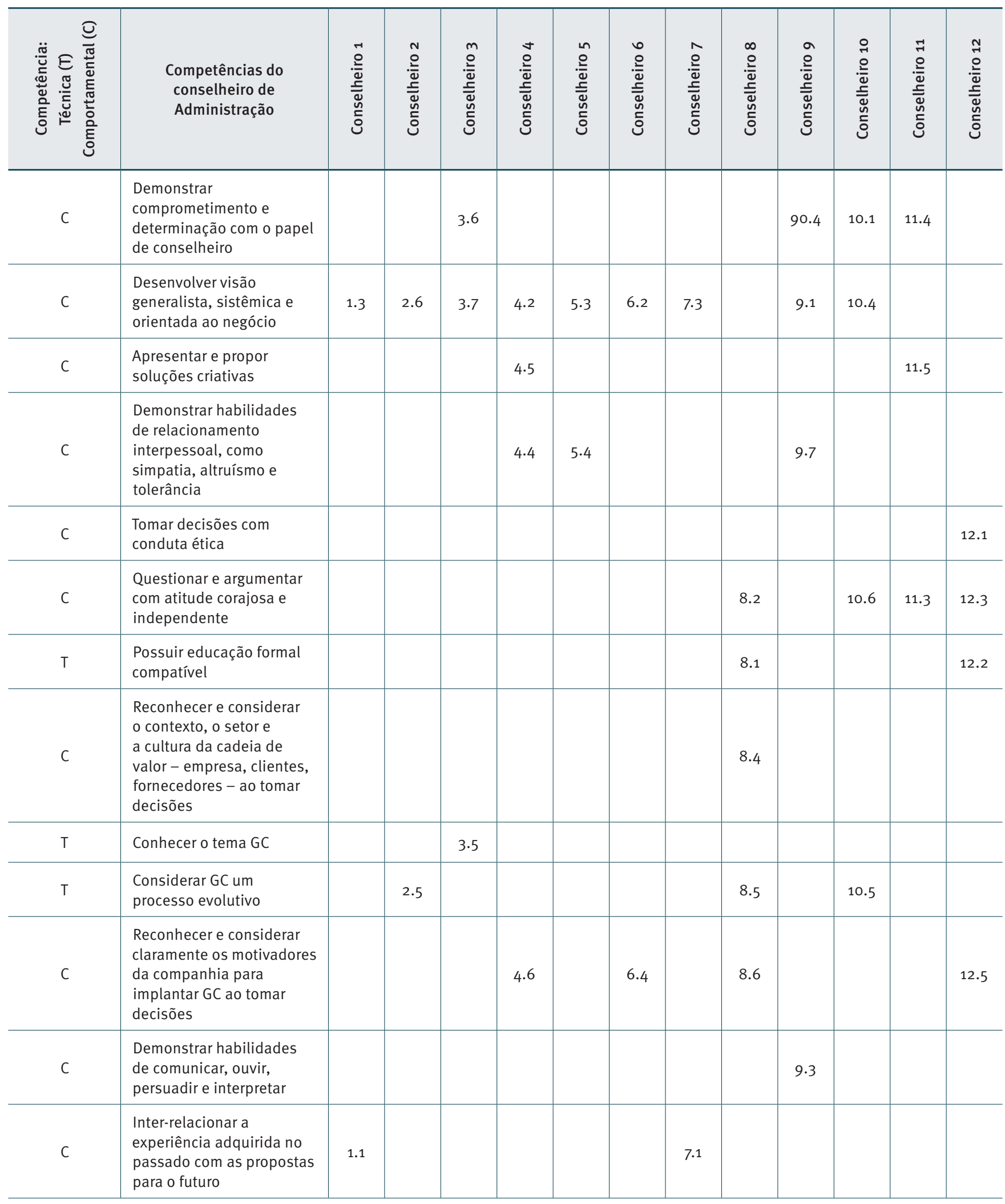


Tabela 1. Competências do conselheiro de Administração

(conclusão)

\begin{tabular}{|c|c|c|c|c|c|c|c|c|c|c|c|c|c|}
\hline 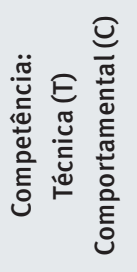 & $\begin{array}{l}\text { Competências do } \\
\text { conselheiro de } \\
\text { Administração }\end{array}$ & 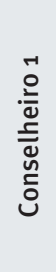 & 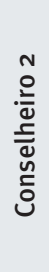 & 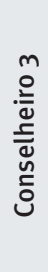 & 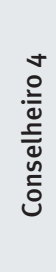 & 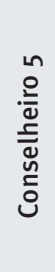 & 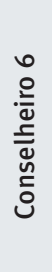 & 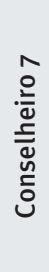 & 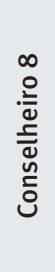 & 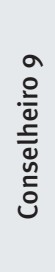 & 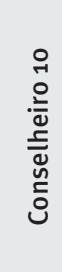 & 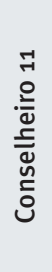 & 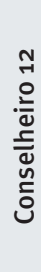 \\
\hline C & $\begin{array}{l}\text { Considerar as expectativas } \\
\text { dos acionistas com relação } \\
\text { aos conselheiros ao tomar } \\
\text { decisões }\end{array}$ & 1.5 & & & 4.3 & & 6.3 & & & & & & \\
\hline C & $\begin{array}{l}\text { Julgar e recomendar } \\
\text { considerando sempre } \\
\text { o melhor interesse da } \\
\text { companhia }\end{array}$ & 1.7 & & & & & & & & & 10.2 & & \\
\hline C & $\begin{array}{l}\text { Capacidade de criticar, } \\
\text { desenvolver e adaptar o } \\
\text { sistema de GC da empresa }\end{array}$ & & & & & & & 7.5 & & & & & \\
\hline $\mathrm{T}$ & $\begin{array}{l}\text { Preparar-se previamente } \\
\text { para as reuniões }\end{array}$ & & & & & & & 7.2 & 8.3 & & & & \\
\hline
\end{tabular}

Na Tabela 1, estão relacionadas as competências que os entrevistados apontaram como críticas ao conselheiro de Administração e, nas colunas ao lado, constam assinalados quais foram os entrevistados que mencionaram as competências. Por exemplo, a competência "Capacidade de adaptar-se para tomada de decisão em colegiado" foi mencionada por quatro dos entrevistados.

Foi feita também uma classificação das competências em duas categorias: competências técnicas e competências comportamentais. Competências técnicas são aquelas que derivam de conhecimentos e habilidades técnicos, e as comportamentais são as que se referem a características de personalidade ou atitude.

Nas células que marcam os entrevistados que mencionaram cada competência, estão códigos (tais como 1.1, 1.2). Esses códigos se referem a frases, ditas pelos entrevistados, que exemplificam cada uma das competências. As frases foram codificadas seguindo o mnemônico X.Y - de identificação, onde:

X: Primeiro número - que indica o código do profissional entrevistado.

Y: Segundo número - o qual indica a sequência numérica das frases coletadas desse entrevistado.
Foram identificadas 21 competências do conselheiro. Destas, 16 competências são comportamentais e cinco competências são técnicas.

A análise das competências mostrou que a competência mais frequente nas entrevistas foi "Desenvolver visão generalista, sistêmica e orientada ao negócio" (Tabela 2). Isso mostra que os entrevistados esperam que os conselheiros sejam generalistas, ao invés de técnicos especialistas em determinada área, como seria o caso de um conselheiro com formação e experiência em apenas uma área. Essa competência permite aos conselheiros contribuir com a organização, trazendo perspectivas e abordagens diferentes para a empresa. Ela também ocorreu como uma das competências mais requeridas para o conselho no estudo realizado por Ingley e Walt (2001).

Em seguida, vem "Demonstrar capacidade de atuar em grupo de forma cooperativa e colaborativa”, com cinco observações. De acordo com Finkelstein e Mooney (2003), essa competência, no caso dos conselhos de Administração, é frequentemente subestimada e, ao mesmo tempo, é uma das que mais influenciam no desempenho do conselho.

A Tabela 2 apresenta a relação completa de competências do conselheiro, ordenadas conforme a frequência de observações. 
Tabela 2. Frequência de ocorrência de citações - Competências do conselheiro

\begin{tabular}{|c|c|c|c|c|}
\hline 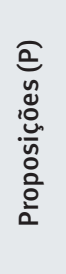 & 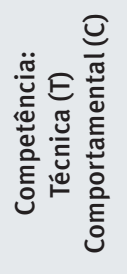 & Competências do conselheiro & 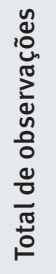 & $\circ$ \\
\hline $\mathrm{P}_{2}$ & C & Demonstrar capacidade de atuar em grupo de maneira cooperativa e colaborativa & 5 & 8,7 \\
\hline $\mathrm{P}_{1}$ & C & Capacidade de adaptar-se para tomada de decisão em colegiado & 4 & 7,0 \\
\hline $\mathrm{P}_{5}$ & C & Demonstrar comprometimento e determinação com o papel de conselheiro & 4 & 7,0 \\
\hline P8 & C & Demonstrar habilidades de relacionamento interpessoal, como simpatia, altruísmo e tolerância & 3 & 5,2 \\
\hline P14 & T & Considerar GC um processo evolutivo & 3 & 5,2 \\
\hline P18 & C & Considerar as expectativas dos acionistas com relação aos conselheiros ao tomar decisões & 3 & 5,2 \\
\hline P4 & $\mathrm{T}$ & Demonstrar conhecimentos práticos sobre conselhos de administração e GC & 2 & 3,5 \\
\hline P7 & C & Apresentar e propor soluções criativas. & 2 & 3,5 \\
\hline P11 & T & Possuir educação formal compatível & 2 & 3,5 \\
\hline P9 & C & Tomar decisões com conduta ética & 1 & 1,7 \\
\hline $\mathrm{P}_{12}$ & C & $\begin{array}{l}\text { Reconhecer e considerar o contexto, o setor e a cultura da cadeia de valor - empresa, clientes, fornecedores } \\
\text { ao tomar decisões }\end{array}$ & 1 & 1,7 \\
\hline P13 & $\mathrm{T}$ & Conhecer o tema GC & 1 & 1,7 \\
\hline P16 & C & Demonstrar habilidades de comunicar, ouvir, persuadir e interpretar & 1 & 1,7 \\
\hline \multirow[t]{2}{*}{$P_{20}$} & C & Capacidade de criticar, desenvolver e adaptar o sistema de GC da empresa & 1 & 1,7 \\
\hline & & & 57 & 100 \\
\hline
\end{tabular}

\section{Características prejudiciais à performance do conselheiro}

A segunda questão do estudo visa identificar as características dos conselheiros que podem ser prejudiciais à sua performance e, em última instância, do conselho como órgão colegiado e da empresa. A Tabela 3 apresenta o resultado da análise das entrevistas para essa questão. Da mesma forma, as características foram classificadas em técnicas e comportamentais. 
Tabela 3. Características prejudiciais à performance dos conselheiros

\begin{tabular}{|c|c|c|c|c|c|c|c|c|c|c|c|c|c|}
\hline 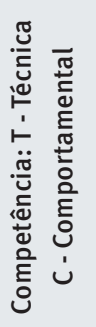 & $\begin{array}{l}\text { Características prejudiciais à } \\
\text { performance dos conselheiros }\end{array}$ & 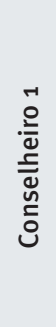 & 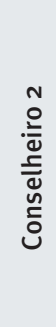 & 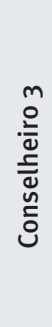 & 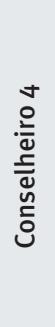 & 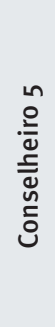 & 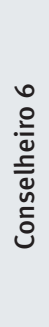 & 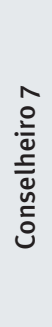 & 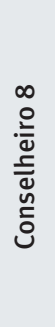 & 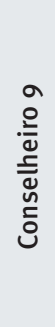 & 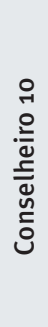 & 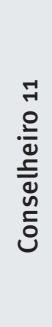 & 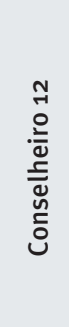 \\
\hline C & $\begin{array}{l}\text { Apego ao poder conferido à } \\
\text { posição de conselheiro }\end{array}$ & 1.9 & & & & & 6.7 & & & & & & \\
\hline C & $\begin{array}{l}\text { Ego, arrogância ou sentimento } \\
\text { de superioridade no exercício } \\
\text { do papel de conselheiro }\end{array}$ & & & & & & & & & & & & 12.6 \\
\hline $\mathrm{T}$ & $\begin{array}{l}\text { A falta de um programa de } \\
\text { educação continuada para o } \\
\text { conselheiro }\end{array}$ & & & & & 5.7 & & & & & & & \\
\hline C & $\begin{array}{l}\text { Baixa capacidade do } \\
\text { conselheiro em confrontar e } \\
\text { questionar }\end{array}$ & & 2.8 & 3.8 & & & & & & & & & 12.7 \\
\hline C & $\begin{array}{l}\text { Dependência emocional do } \\
\text { status que o cargo proporciona }\end{array}$ & & & & & & & & & & & & 12.8 \\
\hline
\end{tabular}

Na Tabela 3, os códigos marcados nas colunas à direita indicam as vezes em que os entrevistados citaram as competências e, ao mesmo tempo, o código atribuído a cada frase.

De maneira semelhante à análise das competências dos conselheiros, aqui também há mais competências comportamentais (quatro) do que competências técnicas (apenas uma). Essas competências foram codificadas a partir das respostas dos entrevistados.

A Tabela 4 mostra as cinco características prejudiciais à performance do conselheiro. Nota-se, primeiramente, que nem todos os entrevistados conseguiram contribuir com essa informação. Esta é uma das razões para a menor quantidade de fatores nesse bloco, quando comparada com aqueles do bloco anterior de competências.

Tabela 4. Frequência de ocorrência de citações - Características prejudiciais à performance dos conselheiros

\begin{tabular}{|c|c|c|c|c|}
\hline 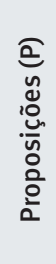 & 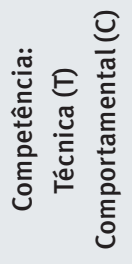 & Características prejudiciais à performance dos conselheiros & 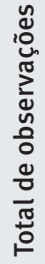 & ๙゚ \\
\hline P22 & C & Apego ao poder conferido à posição de conselheiro & 2 & 25,0 \\
\hline P23 & C & Ego, arrogância ou sentimento de superioridade no exercício do papel de conselheiro & 1 & 12,5 \\
\hline P24 & $\mathrm{T}$ & A falta de um programa de educação continuada para o conselheiro & 1 & 12,5 \\
\hline
\end{tabular}


Em ordem de maior frequência de observações, a Tabela 4 mostra que a característica com maior número de ocorrências é a "Baixa capacidade do conselheiro em confrontar e questionar", seguida de "Apego ao poder conferido à posição de conselheiro".

É interessante notar que quatro das cinco características estão mais associadas à personalidade do conselheiro ou a sua postura diante do conselho do que à sua formação ou capacidade técnica.

\section{Discussão e proposições}

Com base nos resultados apresentados, foi possível formular o modelo apresentado na Figura 1.

\section{Figura 1. Modelo teórico}

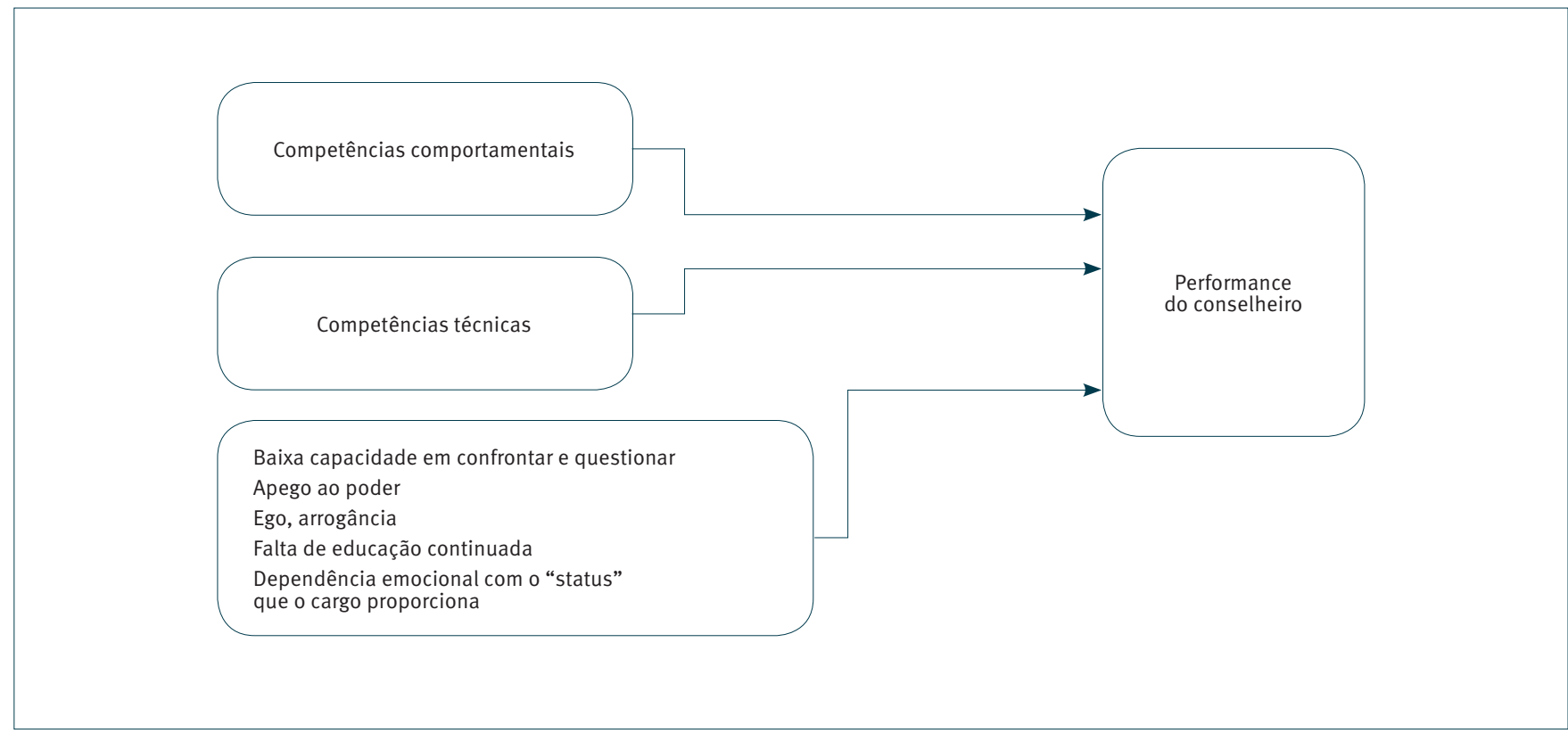

O modelo teórico exposto na Figura 1 propõe que, enquanto competências comportamentais e técnicas influenciam positivamente a performance do conselheiro, existem características de natureza pessoal que atrapalham essa relação positiva: baixa capacidade em confrontar e questionar, apego ao poder, ego e arrogância, falta de educação continuada e dependência emocional do status que o cargo proporciona.

Alinhadas ao modelo, são colocadas a seguir proposições do estudo que derivaram dos achados da pesquisa. Com relação às competências dos conselheiros de Administração, propõe-se que:

- P1. A atuação em grupo de maneira cooperativa e colaborativa influencia positivamente a performance do conselheiro.

- P2. Quanto maior a capacidade de adaptar-se para tomada de decisão em colegiado, maior a influência positiva sobre a performance do conselheiro.
- P3. A capacidade de mediar e resolver conflitos de maneira proativa e construtiva influencia positivamente a performance do conselheiro.

- P4. Possuir conhecimentos práticos sobre conselho e governança corporativa influencia positivamente a performance do conselheiro.

- $\quad$ P5. Demonstrar comprometimento e determinação com o papel de conselheiro influencia positivamente a performance do conselheiro

- P6. Visão generalista, sistêmica e orientada ao negócio influencia positivamente a performance do conselheiro.

- $\quad$ P7. A capacidade de apresentar e propor soluções criativas influencia positivamente a performance do conselheiro. 
- $\quad$ P8. Quanto maior a habilidade de relacionamento interpessoal, maior a influência positiva sobre a performance do conselheiro.

- P9. A conduta ética influencia positivamente a performance do conselheiro.

- P10. Questionar e argumentar com atitude corajosa e independente influencia positivamente a performance do conselheiro.

- P11. A educação formal compatível influencia positivamente a performance do conselheiro.

- P12. Respeitar a cultura da empresa e sua cadeia de valor influencia positivamente a performance do conselheiro.

- P13. Conhecer governança corporativa influencia positivamente a performance do conselheiro.

- $\quad$ P14. Considerar governança um processo evolutivo influencia positivamente a performance do conselheiro.

- P15. Reconhecer e considerar claramente os motivadores da companhia para implantar governança ao tomar decisões influencia positivamente a performance do conselheiro.

- P16. Quanto maior a habilidade de comunicação do conselheiro, maior a influência positiva sobre sua performance.

- P17. Capacidade de traduzir a experiência do passado em futuro influencia positivamente a performance do conselheiro.

- P18. Considerar as expectativas dos acionistas ao tomar decisões influencia positivamente a performance do conselheiro.

- P19. Julgar e recomendar considerando sempre o melhor interesse da companhia influencia positivamente a performance do conselheiro.

- P20. Capacidade de criticar, desenvolver e adaptar o sistema de governança corporativa da empresa influencia positivamente a performance do conselheiro.
- P21. Preparar-se previamente para as reuniões influencia positivamente a performance do conselheiro.

Com relação às características que são prejudiciais à performance do conselheiro, propõe-se que:

- $\quad$ 22. Questões de apego ao poder influenciam negativamente a performance do conselheiro.

- $\quad$ P23. Ego, arrogância ou sentimento de superioridade influenciam negativamente a performance do conselheiro.

- P24. A falta de educação continuada influencia negativamente a performance do conselheiro.

- P25. A baixa capacidade de confrontar e questionar influencia negativamente a performance do conselheiro.

- P26. A dependência emocional do status do cargo influencia negativamente a performance do conselheiro.

Essas proposições têm algumas implicações. A primeira delas é com relação às implicações teóricas para os conselhos de Administração, pois nota-se que, embora boa parte do conhecimento comum sobre a composição do conselho de Administração considere aspectos tais como: a formação dos conselheiros, sua experiência, idade e características técnicas (Baysinger \& Butler, 1985; Beasley, 1996; Klein, 2002), foram as competências comportamentais que obtiveram maior intensidade de citação por parte dos entrevistados. Isso pode sugerir que se atingiu um ponto em que a experiência e a competência técnica já são pré-requisitos aceitos para a escolha de um conselheiro, e que as competências comportamentais são aquilo que os diferencia em termos de performance.

Em segundo lugar, a questão da gestão por competências ainda não foi aplicada de maneira plena no caso dos conselhos de Administração. A presente pesquisa trouxe uma lista de competências dos conselheiros independentes que atuam em empresas de capital fechado. Nota-se, primeiramente, que essa lista de competências é exclusiva desse tipo e perfil de conselheiro. Como se assume na teoria da gestão por competências, estas só fazem sentido quando há um encontro entre as características dos indivíduos (conselheiros independentes, no caso) e das 
organizações - neste caso, brasileiras e de capital fechado. Esse encontro entre necessidades das organizações e características dos indivíduos é a base do sistema de competências e a lógica por trás da geração de valor para as empresas (Zarifian, 2012).

A lista de competências neste estudo obtida pode não atender todos os tipos de organizações, devido à necessidade de se alinharem competências à estratégia (Fernandes, Fleury, \& Mills, 2006) e, por isso, uma investigação mais aprofundada para o caso de cada organização se fará necessária ao se utilizarem as competências aqui listadas especificamente para sua realidade. Além disso, o levantamento das competências é, em si, incompleto; ele passa a gerar valor para as organizações na medida em que as competências levantadas são utilizadas para selecionar profissionais com perfil mais alinhado às empresas, incentivar o desenvolvimento de competências e fazer a gestão do desempenho (Dutra, Hipólito, \& Silva, 200o), no caso, dos conselheiros, conforme o que se é esperado deles em termos de competências listadas. Espera-se, assim, que o levantamento e proposições geradas neste estudo estimulem pesquisas futuras nessas direções - Como selecionar, desenvolver e avaliar o desempenho dos conselheiros, tomando competências como base instrumental? $E$, além disso, que os presentes resultados sirvam como ponto de partida para organizações que queiram estabelecer um processo de gestão de competências para o conselho de Administração e possam tomar como base as competências elencadas neste estudo.

\section{CONSIDERAÇÕES FINAIS}

Esta pesquisa teve como objetivo identificar as competências essenciais para os conselheiros de administração em empresas de capital fechado. Para isso, buscou-se responder às questões: Quais são as competências dos conselheiros de Administração em empresas de capital fechado? E quais são as características dos conselheiros que podem ser prejudiciais à performance do conselheiro e, em última instância, do conselho e da empresa?

Para atender aos objetivos deste trabalho, foi utilizado o método grounded theory (Strauss \& Corbin, 1997). Foram realizadas 12 entrevistas com conselheiros de Administração experientes, que puderam trazer à luz sua opinião sobre as principais competências que consideram importantes para a boa performance de um conselheiro de Administração, bem como apontar as competências que influenciam negativamente essa performance.

Os resultados mostraram um conjunto formado por competências comportamentais em número superior ao de competências técnicas para os conselheiros. Esse resultado expande o conhecimento atual sobre o perfil dos conselheiros, que até então tem focado prioritariamente diversidade, complementariedade, formação, experiência e outras características técnicas.

Além desse resultado, foram identificados também cinco fatores que prejudicam a performance do conselheiro: Baixa capacidade em confrontar e questionar, Apego ao poder; Ego, arrogância, Falta de educação continuada e Dependência emocional do status que o cargo proporciona.

Como é objetivo dos estudos de grounded theory, os achados foram sintetizados em um modelo teórico, que foi gerado a partir dos dados, e em proposições do estudo. Em futuros estudos, sugere-se que as proposições aqui delineadas possam ser testadas quantitativamente.

Como limitações deste estudo, tem-se a subjetividade na análise dos dados, característica das pesquisas qualitativas, e as limitações da amostra teórica utilizada, não probabilística nem representativa de universo. Assim, as proposições podem servir de base para futuros estudos dedutivos que envolvam os testes dessas proposições.

Conclui-se que existe um vasto campo de atividades e pesquisas que podem ser desenvolvidas com a perspectiva das competências comportamentais do conselheiro de Administração. Espera-se que o presente estudo inspire futuras investigações de teste de teorias e iniciativas profissionais no sentido de melhorar a competência dos conselheiros e, em última instância, a performance das organizações.

\section{REFERÊNCIAS}

Albuquerque, L. G., \& Oliveira, P. M. (2010). Competências ou cargos: Uma análise das tendências das bases para o instrumental de recursos humanos. Caderno de Pesquisas em Administração, 8(4), 13-25.

Alshareef, M. N. Z., \& Sandhu, K. (2015). Adoption of corporate social responsibility: Board competencies and roles. International Journal of Business and Management, 10(6), 75-89. doi:10.5539/ijbm. v10n6p75

Anderson, D. W., Melanson, S. J., \& Maly, J. (2007). The evolution of corporate governance: Power redistribution brings boards to life. Corporate Governance: An International Review, 15(5), 780-797. doi:10.1111/j.1467-8683.2007.00608.x

Andre, R. S. (2010). Competências de conselho tutelar: Alcances e limites. $12^{\circ}$ Seminário de Iniciação Científica e Extensão da UEMG, Belo Horizonte, MG.

Aragão, J. W. M. de. (2003). Os conselhos municipais do FUNDEF: Gestão democrática e controle social (Tese de doutorado em Educação, Programa de Pós-Graduação em Educação, Universidade Federal da Bahia, Salvador). 
Bardin, L. (2011). Análise de conteúdo. Lisboa, Portugal: Edições 70.

Baysinger, B. D., \& Butler, H. N. (1985). Corporate governance and the board of directors: Performance effects of changes in board composition. Journal of Law, Economics, \& Organization, 1(1),101-124.

Beasley, M. S. (1996). An empirical analysis of the relation between the board of director composition and financial statement fraud. Accounting Review, 71(4), 443-465.

Berezinets, I., Garanina, T., \& Ilina, Y. (2016). Intellectual capital of a board of directors and its elements: Introduction to the concepts. Journal of Intellectual Capital, 17(4), 632-653. doi:10.1108/JIC-012016-0003

Brandão, H., \& Babry, C. P. (2005). Gestão por competências: Métodos e técnicas para mapeamento de competências. Revista do Serviço Público, 56(2), 179-194. doi:10.21874/rsp.v56i2.224

Brandão, H., \& Guimarães, T. A. (2001). Gestão de competências e gestão de desempenho: Tecnologias distintas ou instrumentos de um mesmo construto? RAE-Revista de Administração de Empresas, 41(1), 8-15. doi:10.1590/S0034-75902001000100002

Brandão, H. P., Zimmer, M. V., Pereira, C. G., Marques, F., Costa, H. V., Carbone, P. P., \& Almada, V. F. (2008). Gestão de desempenho por competências: Integrando a gestão por competências, o balanced scorecard e a avaliação 360 graus. RAP-Revista de Administração Pública, 42(5), 875-898. doi:10.1590/S0034-76122008000500004

Breckenridge, J., \& Jones, D. (2009). Demystifying theoretical sampling in grounded theory research. The Grounded theory Review: An International Journal, 8(2), 113-126.

Charan, R., Useem, M., \& Carey, B. (2014). Governança ativa: As vantagens de uma liderança compartilhada entre conselheiros $e$ executivos. Rio de Janeiro, RJ: Elsevier.

Charmaz, K., \& Belgrave, L. L. (2012). Qualitative interviewing and grounded theory analysis. In The SAGE Handbook of Interview Research: The Complexity of the Craft (pp. 347-366). SAGE Publications Inc. doi: 10.4135/9781452218403.n25

Child, J., \& Rodrigues, S. (2003). The international crisis of confidence in corporations. Journal of Management \& Governance, 7(3), 233-240. doi:10.1023/A:1025062422500

Cocks, G., Mueller, J., Ingley, C., \& Rennie, M. (2015, September). Competence Gaps in Company Directors in New Zealand. ToulonVerona Conference "Excellence in Services". Recuperado de http:// www.toulonveronaconf.eu/papers/index.php/tvc/article/view/242

Collins, R. G. (2004). Aconselhamento cristão: Século XXI. São Paulo, SP: Vida Nova.

Dutra, J. S. (2002). Gestão de pessoas: Modelo, processos, tendências e perspectivas. São Paulo, SP: Atlas.

Dutra, J. S., Hipólito, J. A. M., \& Silva, C. M. (2000). Gestão de pessoas por competências: 0 caso de uma empresa do setor de telecomunicações. RAC-Revista de Administração Contemporânea, 4(1), 161-176. doi:10.1590/S1415-65552000000100009

Enache, L., Parbonetti, A., \& Srivastava, A. (2015). Are all independent directors created equal? Do their professional backgrounds influence firms' financial disclosures? Evidence from biotechnology firms [Working paper]. Recuperado de http://researcharchive.vuw.ac.nz/ $\mathrm{xmlui} /$ bitstream/handle/10063/4145/paper.pdf? sequence $=1$
Fernandes, B. H. R., Fleury, M. T., \& Mills, J. (2006). Construindo o diálogo entre competência, recursos e desempenho organizacional. $R A E$ Revista de Administração de Empresas, 46(4), 48-65. doi:10.159o/ So034-75902006000400006

Finkelstein, S., \& Mooney, A. C. (2003). Not the usual suspects: How to use board process to make boards better. Academy of Management Perspectives, 17(2), 101-113.

Fleury, M. T., \& Fleury, A. C. (2004). Alinhando estratégia e competências. RAE-Revista de Administração de Empresas, 44(1), 44-57. doi:10.1590/ So034-75902004000100012

Glaser, B. G., \& Strauss, A. L. (1967). The discovery of grounded theory: Strategies for qualitative research. Chicago, USA: Aldine.

Hambrick, D. C., \& Mason, P. A. (1984). Upper echelons: The organization as a reflection of its top managers. The Academy of Management Review, 9(2), 193-206.

Hambrick, D. C., Misangyi, V. F., \& Park, C. A. (2015). The quad model for identifying a corporate director's potential for effective monitoring: Toward a new theory of board sufficiency. Academy of Management Review, 40(3), 323-344. doi:10.5465/amr.2014.0066

Ingley, C. B., \& Walt, N. T. Van Der. (2001). The strategic board: The changing role of directors in developing and maintaining corporate capability. Corporate Governance: An International Review, 9(3), 174185. doi:10.1111/1467-8683.00245

Instituto Brasileiro de Governança Corporativa. (2015). Código de boas práticas de governança corporativa. Recuperado de http://www.ibgc. org.br/inter.php?id=18163

Klein, A. (2002). Audit committee, board of director characteristics, and earnings management. Journal of Accounting and Economics, 33(3), 375-400. doi:10.1016/S0165-4101(02)00059-9

Lado, A. A., \& Wilson, M. C. (1994). Human resource systems and sustained competitive advantage: A competency-based perspective. Academy of Management Review, 19(4), 699-727.

Lucas, A. J., Lúcio, L. P., \& Sá, A. C. (2009). O entendimento dos conselheiros do Conselho Regional de Enfermagem de São Paulo sobre a aplicação dos princípios da bioética na análise dos processos éticos. Revista do Instituto de Ciências da Saúde, 27(4), 318-323.

Martin, P. Y., \& Turner, B. A. (1986). Grounded theory and organizational research. The Journal of Applied Behavioral Science, 22(2), 141-157. doi:10.1177/002188638602200207

McClelland, D. C. (1973). Testing for competence rather than for "intelligence". The American Psychologist, 28(1), 1-14. doi:10.1037/ hoo34092

Morilha, A. (2014). Competências no aconselhamento. Revista Teológica (on-line), 6(7), 104-110.

Nadkarni, S., \& Herrmann, P. O. L. (2010). CEO personality, strategic flexibility, and firm performance: The case of the Indian business process outsourcing industry. Academy of Management Journal, 53(5), 1050-1073. doi:10.5465/AMJ.2010.54533196

Nicholson, G. J., \& Kiel, G. C. (2004). A framework for diagnosing board effectiveness. Corporate Governance: An International Review, 12(4), 442-46o. doi:10.1111/j.1467-8683.2004.00386.x

Parry, S. B. (1998). Just what is a competency? (and why should you care?). Training, 35(6), 58-64.

Prahalad, C. K., \& Hamel, G. (1990). The core competence of the corporation. Harvard Business Review, 68(3), 79-91. Recuperado de https://hbr.org 
Pratt, M. G. (2009). From the editors: For the lack of a boilerplate: Tips on writing up (and reviewing) qualitative research. Academy of Management Journal, 52(5), 856-862. doi:10.5465/ AMJ.2009.44632557

Resick, C. J. Whitman, D. S., Weingarden, S. M., \& Hiller, N. J. (2009). The bright-side and the dark-side of CEO personality: Examining core self-evaluations, narcissism, transformational leadership, and strategic influence. Journal of Applied Psychology, 94(6), 1365-1381. doi:10.1037/a0016238

Rodrigues, J. F., Jr. (1998). A taxonomia de objetivos educacionais. Brasília: Editora UNB.

Singleton, R. A., \& Straits, B. C. (1999). Approaches to social research (Vol. 54, 3rd ed.). New York, USA: Oxford University Press.

Sonsini, L. (2011). Tensions in the boardroom in 2011: A perspective from Wilson Sonsini Goodrich \& Rosati. The Corporate Governance Advisor, 19(2). Recuperado de https://www.wsgr.com/wsgr/
Stern, P. N. (1980). Grounded theory methodology: Its uses and processes. Journal of Nursing Scholarship, 12(1), 20-23. doi:10.1111/j.1547-5069.1980.tb01455.x

Strauss, A. L., \& Corbin, J. M. (1997). Grounded theory in practice. California, USA: Sage Publications.

Sur, S., Lvina, E., \& Magnan, M. (2013). Why do boards differ? Because owners do: Assessing ownership impact on board composition. Corporate Governance: An International Review, 21(4), 373-389. doi:10.1111/corg.12021

Yermack, D. (1996). Higher market valuation of companies with a small board of directors. Journal of Financial Economics, 40(2), 185-211. doi:10.1016/0304-405X(95)00844-5

Yoshikawa, T., \& Hu, H. W. (2015). Organizational citizenship behaviors of directors: An integrated framework of director role-identity and boardroom structure. Journal of Business Ethics, 143(1), 99-109.

Zarifian, P. (2012). Objetivo competência: Por uma nova lógica. São Paulo, SP: Atlas. 